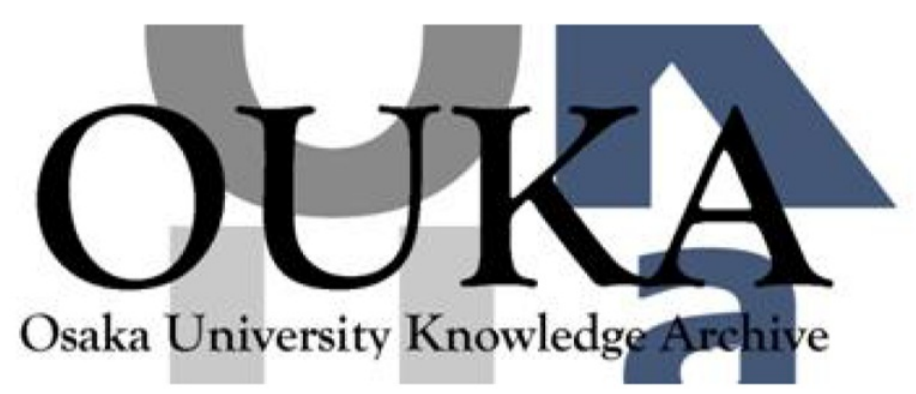

\begin{tabular}{|c|l|}
\hline Title & $\begin{array}{l}\text { Paper-Based Disposable Molecular Sensor } \\
\text { Constructed from Oxide Nanowires, Cel lulose } \\
\text { Nanofibers, and Penci l-Drawn Electrodes }\end{array}$ \\
\hline Author(s) & $\begin{array}{l}\text { Koga, Hirotaka; Nagashima, Kazuki; Huang, } \\
\text { Yintong et al. }\end{array}$ \\
\hline Citation & $\begin{array}{l}\text { ACS Applied Materials and Interfaces. 11(16) } \\
\text { p. 15044-p. 15050 }\end{array}$ \\
\hline Issue Date & $2019-04-24$ \\
\hline oaire:version & AM \\
\hline URL & https://hdl. handle.net/11094/78436 \\
\hline rights & Copyright $\odot 2019$ American Chemical Society \\
\hline Note & \\
\hline
\end{tabular}

Osaka University Knowledge Archive : OUKA

https://ir. Library. osaka-u. ac. jp/

Osaka University 


\section{Paper-based disposable molecular sensor constructed from oxide nanowires, cellulose nanofibers, and pencil-drawn electrodes}

Hirotaka Koga, ${ }^{* \dagger}$ Kazuki Nagashima, ${ }^{*}$, Yintong Huang§, Guozhu Zhang, ${ }^{\ddagger}$ Chen Wang, ${ }^{\ddagger}$ Tsunaki Takahashi, ${ }^{\ddagger}$ Akihide Inoue, ${ }^{\ddagger}$ Hong Yang, ${ }^{\star}$ Masaki Kanai, ${ }^{\ddagger}$ Yong He,\| Kojiro Uetani, ${ }^{\dagger}$ Masaya Nogi ${ }^{\dagger}$ and Takeshi Yanagida

†The Institute of Scientific and Industrial Research, Osaka University, 8-1 Mihogaoka, Ibaraki, Osaka 567-0047, Japan

¥nstitute for Materials Chemistry and Engineering, Kyushu University, 6-1 Kasuga-Koen, Kasuga, Fukuoka 816-8580, Japan

§Graduate School of Engineering, Osaka University, 8-1 Mihogaoka, Ibaraki, Osaka 567-0047, Japan

$\|$ Key Laboratory of Optoelectronic Technology and Systems of the Education Ministry of China, College of Optoelectronic Engineering, Chongqing University, Chongqing, 400044, China

\section{Keywords}

Cellulose nanofiber, Oxide nanowire, Nanocomposite, $\mathrm{NO}_{2}$ sensor, Paper electronics 


\begin{abstract}
Progress toward the concept of "a trillion sensor universe" requires sensor devices to become more abundant, ubiquitous, and be potentially disposable. Here, we report a paper-based disposable molecular sensor device constructed from a nanowire sensor based on common zinc oxide ( $\mathrm{ZnO})$, a wood-derived biodegradable cellulose nanofiber paper substrate, and a low-cost graphite electrode. The $\mathrm{ZnO}$ nanowire/cellulose nanofiber composite structure is embedded in the surface of the cellulose nanofiber paper substrate via a two-step papermaking process. This structure provides a mechanically robust and efficiently bridged network for the nanowire sensor, while ensuring efficient access to target molecules and allowing reliable electrical contact with electrodes. The as-fabricated paper sensor device with pencil-drawn graphite electrodes exhibits efficient resistance change-based molecular sensing of $\mathrm{NO}_{2}$ as a model gas. The performance of our device is comparable to that of noble metal electrodes. Furthermore, we demonstrate cut-andpaste usability and easy disposal of the sensor device with its uniform in-plane sensing properties. Our strategy offers a disposable molecular sensing platform for use in future sensor network technologies.
\end{abstract}




\section{Introduction}

The recent rapid growth of the Internet of Things (IoT) has generated considerable interest in sensor technologies. ${ }^{1,2}$ Global usage of sensor devices is estimated to reach more than one trillion units per year by $2022 .{ }^{3}$ In particular, molecular sensing has become a core technology of the IoT, because it offers a powerful tool for generating data to be used in a wide range of fields such as healthcare, environmental monitoring, and industrial safety. ${ }^{2,4}$ The collection of molecular information by sensors will open a new platform for generating chemical "big data" within a trillion-sensor society. To collect accurate molecular information over long periods, reliable molecular sensing approaches are required.

To effectively detect volatile molecules, various types of molecular sensors such as polymerbased chemiresistor sensors, ${ }^{5}$ two-dimensional nanosheet sensors, ${ }^{6}$ and inorganic nanomaterialbased sensors ${ }^{7}$ have been demonstrated. Among these, semiconducting metal oxides show promise from the viewpoint of long-term molecular sensing owing to their thermal/chemical stability in air. ${ }^{8}$ The sensing mechanism of conventional metal oxide sensors is mainly based on changes in the electric potential at grain-boundaries upon exposure to target molecules. However, such mechanisms frequently suffer from deteriorated sensing performances owing to contamination of grain-boundaries during long-term use. ${ }^{9,10}$ Disposable sensor devices might effectively overcome the problem of deteriorating device performance in long-term use. A sensor component suitable for single- or short-term use, could be easily replaced with a fresh component before it deteriorates. Such sensor devices are required to not only be disposable but should also be lightweight, inexpensive, and mechanically robust to handling. These features cannot be achieved in conventional powder-formed metal oxide sensors equipped with precious metal electrodes. $^{11}$

In this study, we propose a disposable sensor device constructed from a cellulose nanofiber 
paper substrate, a zinc oxide $(\mathrm{ZnO})$ nanowire sensor, and a graphite electrode. Cellulose nanofiber paper is expected to be beneficial for disposable sensors, because it is lightweight, thermally/mechanically robust and made from abundant and renewable biomass resources. ${ }^{12,13}$ In previous studies, various cellulose nanofiber paper-based electronic devices, such as transparent conductive films, ${ }^{14,15}$ transistors, ${ }^{16,17}$ antennas, ${ }^{18,19}$ memory, ${ }^{20,21}$ generators, ${ }^{22}$ and electronic paper $^{23}$ have been developed. Such paper-based devices show high performance, paper-like flexibility, and biodegradability. ${ }^{24,25}$ For sensing materials, single crystalline nanowires of highly abundant metal oxides (e.g., $\mathrm{ZnO}$ and $\mathrm{CuO}$ ) have shown great promise as molecular sensors, owing to their large surface/volume ratios and well-defined crystal planes, wide controllability of chemical reactivity by altering the metal ions, ${ }^{26-28}$ and high mechanical robustness. ${ }^{29}$ Graphite is also suitable as a disposable electrode for molecular sensors because of its low-cost and high stability in air.

From this perspective, the integration of an oxide nanowire sensor, a cellulose nanofiber paper substrate, and a graphite electrode represents a reasonable approach to disposable molecular sensor devices. However, conventional strategies, such as the encapsulation of nanowires or drop casting of nanowires into/onto cellulose nanofiber paper, are unsuitable for molecular sensors, because analytes are not accessible to the oxide nanowires or the nanowires easily peel off from the substrate. One essential requirement is strongly adhered networks of oxide nanowire sensors on the surfaces of the cellulose nanofiber paper substrate. To meet these requirements, here, we tailored robust nanowire/cellulose nanofiber composite networks, which are implanted on the surfaces of cellulose nanofiber paper substrates, by a two-step papermaking process. The asimplanted $\mathrm{ZnO}$ nanowires provide strongly adhesive and efficiently bridged network structures on the substrate surface, and enable reliable electrical contact with graphite electrodes (Figure 1). The as-fabricated paper device showed effective molecular sensing performance for nitrogen 
oxide $\left(\mathrm{NO}_{2}\right)$ as a model gas component. The performance of our device was comparable to that of Pt electrode-based systems. The paper-like cut-and-paste usability of the sensor device with an in-plane uniformity of the sensing property was also demonstrated, suggesting potential for application as disposable and ubiquitous molecular sensor elements.

\section{Results and Discussion}

In this study, the sensing material was hydrothermally synthesized single crystalline $\mathrm{ZnO}$ nanowires with widths and lengths of approximately $100 \mathrm{~nm}$ and $6 \mu \mathrm{m}$, respectively (see Supporting Information Figure S1). ${ }^{30}$ We first investigated the robust integration of the $\mathrm{ZnO}$ nanowires with the substrate materials. When the $\mathrm{ZnO}$ nanowires were drop-coated on to a conventional substrate, i.e., polyethylene terephthalate (PET) film, they were easily peeled off by a finger touch, even after a hot-pressing treatment at $110{ }^{\circ} \mathrm{C}$ for $1 \mathrm{~h}$ under high pressure $(8.5$ MPa) (Figure 2a and d). The adhesion of the $\mathrm{ZnO}$ nanowires was improved with the use of the cellulose nanofiber paper substrate (Figure $2 \mathrm{~b}$ ) and the $\mathrm{ZnO}$ nanowires adhered to the cellulose nanofiber paper substrate much better than to the PET film substrate. However, a small amount of $\mathrm{ZnO}$ nanowires was removed by a finger touch. Thus, simply coating the $\mathrm{ZnO}$ nanowires onto the substrate did not result in strong adhesion. To overcome this problem, we deposited the $\mathrm{ZnO}$ nanowire/cellulose nanofiber composite networks onto the cellulose nanofiber paper substrate by a two-step papermaking process, as follows (see Supporting Information Figure S2). First, an aqueous dispersion of wood cellulose nanofibers with widths $15-50 \mathrm{~nm}$ was filtered through a commercial membrane filter to form a wet cellulose nanofiber gel. Second, an aqueous dispersion of $\mathrm{ZnO}$ nanowires with cellulose nanofibers was poured onto the wet nanofiber gel, followed by dewatering under pressure filtration. During the second process, the wet nanofiber gel served as a filter, retaining almost all the $\mathrm{ZnO}$ nanowires on the surface. Finally, the resulting wet material 
was thoroughly dried by hot pressing at $110{ }^{\circ} \mathrm{C}$ for $1 \mathrm{~h}(8.5 \mathrm{MPa})$ and then peeled from the membrane filter to form a sheet of paper. The as-prepared $\mathrm{ZnO}$ nanowire/cellulose nanofiber composite networks on the cellulose nanofiber paper, denoted as $\mathrm{ZnO}$ nanowire@cellulose nanofiber paper, were sufficiently adhesive to withstand finger touch (Figure $2 \mathrm{c}$ and e). We attribute this stability to the entanglement of $\mathrm{ZnO}$ nanowires and cellulose nanofibers on the surfaces of the cellulose nanofiber paper substrate (Figure 3a and b). Atomic absorption analysis confirmed that the $\mathrm{ZnO}$ content in the $\mathrm{ZnO}$ nanowire@cellulose nanofiber paper was ca. $5.5 \mathrm{wt} \%$. Thus, our approach is expected as an effective way to construct mechanically robust $\mathrm{ZnO}$ nanowire networks on cellulose nanofiber paper substrates.

Formation of a $\mathrm{ZnO}$ nanowire network on the substrate surface is also important to ensure efficient molecular sensing response (i.e., a detectable change in the electrical resistance upon adsorption/desorption of analytes). The network can offer additional modulation to the sensor resistance owing to the potential barrier at the nanowire/nanowire junctions as well as the surfaces of individual nanowires. ${ }^{31}$ Field-emission scanning electron microscope (FE-SEM) and energy dispersive X-ray spectrometry (EDX) images of the surface and a cross section of the ZnO nanowire@cellulose nanofiber paper are shown in Figure 3c-f. The EDX Zn element mapping images show that the $\mathrm{ZnO}$ nanowires were well-dispersed and implanted over the whole surface of the cellulose nanofiber paper substrate (see also Supporting Information Figures S3 and S4). The cellulose nanofiber paper without $\mathrm{ZnO}$ nanowires showed a surface resistance as high as $10^{14} \Omega$ square $^{-1}$ owing to the high electrical insulation properties of the cellulose nanofibers. ${ }^{25}$ The $\mathrm{ZnO}$ nanowire@cellulose nanofiber paper exhibited a relatively low surface resistance of approximately $1.0 \times 10^{8} \Omega$ square $^{-1}$ under atmospheric conditions. These results indicated successful formation of efficiently bridged networks of $\mathrm{ZnO}$ nanowires in the cellulose nanofiber paper substrate. When an aqueous mixture of $\mathrm{ZnO}$ nanowires and cellulose nanofibers 
was introduced into the paper by a one-step papermaking process, most of the $\mathrm{ZnO}$ nanowires were buried inside the cellulose nanofiber matrix, leading to difficulty in forming a nanowirebridging structure on the cellulose nanofiber paper (see Supporting Information Figure S5). Thus, the ZnO nanowire@cellulose nanofiber paper with a dual-layered structure (Figure 3), which was prepared by a two-step papermaking approach (Figure S2), provided a robust nanowire-bridging structure over its entire surface.

The ZnO nanowire@cellulose nanofiber paper was used as a molecular sensing platform for $\mathrm{NO}_{2}$ as a model gas component. When the n-type $\mathrm{ZnO}$ semiconductor is exposed to an oxidizing gas such as $\mathrm{NO}_{2}$, gas molecules adsorb to the $\mathrm{ZnO}$ surface and extract electrons from the conduction band of $\mathrm{ZnO}$, leading to the formation of an electron-depletion region on the surface. ${ }^{32}$ Furthermore, in the case of a $\mathrm{ZnO}$ nanowire sensor, a potential barrier develops at nanowire/nanowire junctions of the bridging nanowire network, which blocks electron flow more efficiently than surface depletion of a single nanowire and thus enhances sensitivity (i.e., induces an effective increase in the resistance). ${ }^{31}$ To evaluate the sensing performance of the $\mathrm{ZnO}$ nanowire@cellulose nanofiber paper, Pt electrodes were first sputtered on the surfaces of the paper to fabricate the paper sensor device (Figure 4a). The paper sensor showed ohmic behavior in current-voltage characteristics, indicating the formation of good electrical contacts between the $\mathrm{ZnO}$ nanowire sensor networks and Pt electrodes (see Supporting Information Figure S6). The sensing performance of the paper sensor for $98 \mathrm{ppm} \mathrm{NO}_{2}$ at $150{ }^{\circ} \mathrm{C}$ is shown in Figure $4 \mathrm{~b}$. The electrical resistance of the $\mathrm{ZnO}$ nanowire@cellulose nanofiber paper clearly increased upon exposure to $98 \mathrm{ppm} \mathrm{NO}_{2}$ gas. Then, following exposure to air, the resistance decreased owing to desorption of $\mathrm{NO}_{2}$ from the $\mathrm{ZnO}$ nanowires. These results suggested that the $\mathrm{ZnO}$ nanowirebridging structure on the cellulose nanofiber paper substrate (Figures $3 \mathrm{~d}$ and $\mathrm{S} 3$ ) enabled $\mathrm{NO}_{2}$ sensing. The paper sensor provided sufficient sensitivity to detect $\mathrm{NO}_{2}$ down to concentrations as 
low as $3.9 \mathrm{ppm}$ (Figure $4 \mathrm{c}$ and $\mathrm{d}$ ). The $\mathrm{NO}_{2}$ sensing characteristics of the $\mathrm{ZnO}$ nanowire@cellulose nanofiber paper were almost similar up to $30 \%$ of relative humidity (RH $30 \%$ ), while further increase of relative humidity decreased its sensitivity (Figure S7). This is plausibly because the adsorption of $\mathrm{NO}_{2}$ molecules was suppressed by the presence of water molecules on the surfaces of $\mathrm{ZnO}$ nanowires. However, the $\mathrm{ZnO}$ nanowire@cellulose nanofiber paper still could detect $28 \mathrm{ppm} \mathrm{NO}_{2}$ at $\mathrm{RH} 70 \%$.

As described above, the adsorption/desorption behaviors of $\mathrm{NO}_{2}$ onto/from $\mathrm{ZnO}$ nanowires govern their sensing performances. As shown in Figure $4 \mathrm{e}$, the $\mathrm{NO}_{2}$ sensing behavior of the paper sensor depended on the surrounding temperatures, indicating that temperature affected the adsorption/desorption of $\mathrm{NO}_{2}$ onto/from the $\mathrm{ZnO}$ nanowire-bridging structure. The relative resistance values of the paper sensor after the first exposure to $98 \mathrm{ppm} \mathrm{NO}$ for $10 \mathrm{~s}\left(\mathrm{NO}_{2}\right.$ introduction) and the following exposure to air for $10 \mathrm{~s}\left(\mathrm{NO}_{2}\right.$ subtraction) at different temperatures are shown in Figure 4f. Upon introducing $\mathrm{NO}_{2}$, the relative resistance values increased with increasing temperature, suggesting that $\mathrm{NO}_{2}$ adsorption onto the $\mathrm{ZnO}$ nanowires was promoted as the surrounding temperature increased. At temperatures below $50{ }^{\circ} \mathrm{C}$, the relative resistance values were greater than 1.0 for both the introduction of $\mathrm{NO}_{2}$ and its attempted removal under an air flow, indicating that $\mathrm{NO}_{2}$ hardly desorbed from $\mathrm{ZnO}$ nanowires at low temperatures. These results suggest that low-temperature use of the paper sensor can improve sensitivity (resistance change) for single-use and long-term sensing. When the paper sensor was used at relatively high temperatures exceeding $100{ }^{\circ} \mathrm{C}$, the relative resistance values were less than 1.0 upon loss of $\mathrm{NO}_{2}$, owing to the promotion of $\mathrm{NO}_{2}$ desorption from the $\mathrm{ZnO}$ nanowires. Because both adsorption and desorption of $\mathrm{NO}_{2}$ onto and from the $\mathrm{ZnO}$ nanowire-bridging structure occurred over $100{ }^{\circ} \mathrm{C}$, such high-temperature use of the paper sensor would be 
advantageous for short-term and repeat sensing. Thus, the paper sensor is expected to be suitable for single-use at room temperatures and repeated use at high temperatures over $100{ }^{\circ} \mathrm{C}$.

Although the ZnO nanowire@cellulose nanofiber paper acted as a molecular sensing platform, the use of precious metal electrodes (i.e., Pt) prevents easy disposal of the sensor device. One of the most important properties of electrodes for gas sensors is stability to air. However, inexpensive metals, such as aluminum, copper, and titanium, easily form an insulation layer on their surfaces owing to oxidation in air, which limits their applicability as electrodes. Graphite is a promising candidate for disposable electrodes, because it is earth-abundant, low-cost, and airstable. Therefore, we investigated graphite as an electrode for the $\mathrm{ZnO}$ nanowire@cellulose nanofiber paper. Pencil lead generally contains high-purity graphite. As shown in Figure 5a and b, graphite electrodes, drawn from a commercial pencil lead, were successfully deposited onto the surfaces of the ZnO nanowire@cellulose nanofiber paper by a drawing process. The success of the pencil drawing can be attributed to both the nanoscale rough surfaces (Figure $3 b$ ) and high mechanical robustness (Figure 2c and e) of the ZnO nanowire@cellulose nanofiber paper. The electrical resistance of the pencil-drawn graphite electrodes was of the order of $10^{4} \Omega$, which is much lower than that of the sensing layer, i.e., ZnO nanowire@cellulose nanofiber paper $(1.0 \times$ $10^{8} \Omega$ square $\left.^{-1}\right)$. In addition, the as-prepared paper sensor exhibited ohmic behavior in its currentvoltage characteristics, suggesting the formation of a reliable electrical contact between the $\mathrm{ZnO}$ nanowire sensor networks and graphite electrodes (see Supporting Information Figure S8). The paper sensor with pencil-drawn graphite electrodes showed good $\mathrm{NO}_{2}$ sensing performance, comparable to that of the Pt electrodes (Figure 5c). It has been reported that flexible pencil lead composed of graphite/polymer composites can act as a sensing material for volatile organic compounds owing to absorption/desorption-induced swelling/recovery of polymer binders. ${ }^{33}$ The pencil-drawn graphite used in this study showed no clear sensitivity toward $\mathrm{NO}_{2}$ gas, indicating 
that the graphite behaved as an electrode rather than a sensing layer (Figure S9). Thus, we constructed a paper sensor device based on graphite electrodes rather than precious metal electrodes, while maintaining the molecular sensing performance of the device.

Furthermore, the $\mathrm{ZnO}$ nanowire@cellulose nanofiber paper was easily shaped, as for normal paper. The paper could be easily cut with scissors into a desired shape. Then graphite electrodes were formed on the paper by simply drawing with a pencil, before application as a $\mathrm{NO}_{2}$ sensor (Figure 5d). As shown in Figure 5e, these paper sensors showed similar $\mathrm{NO}_{2}$ sensing performance, regardless of the area of the cut-out. We attribute this result to the high spatial uniformity of the $\mathrm{ZnO}$ nanowire networks on the cellulose nanofiber paper. As shown in Figure 6, the paper sensor could also be disposed of simply and rapidly, through burning within several seconds. Such cut-and-paste usability and easy disposal are features required for a ubiquitous molecular sensor network; our paper sensor is light and could be easily cut into a range of shapes and sizes, and mounted as required for sensing, and disposed after use. Integration of the heating system into the paper sensor without sacrificing its flexibility and disposability is a further challenge. Drawing graphite layer all over the back surfaces of the ZnO nanowire@cellulose nanofiber paper might be a promising strategy; the as-drawn graphite layer would allow joule heating of the sensing layer.

\section{Conclusion}

To conclude, we fabricated a paper-based disposable molecular sensor device. A cellulose nanofiber paper substrate, $\mathrm{ZnO}$ nanowire sensor, and graphite electrodes were robustly integrated by two-step papermaking and pencil-drawing processes. The as-fabricated paper sensor device offered efficient molecular sensing performance for $\mathrm{NO}_{2}$, cut-and-paste usability, and easy 
disposability. This strategy can be extended to a variety of oxide nanowires and thus spur development of disposable molecular sensors to support a future trillion-sensor society.

\section{Experimental Section}

Materials. Cellulose nanofibers with widths 15-50 nm were prepared from never-dried softwood dissolving sulfite pulp, which was provided by Nippon Paper Group. Inc., Tokyo, Japan, as follows. An aqueous suspension of the pulp $(0.5 \mathrm{wt} \%, 2 \mathrm{~L})$ was treated by a high-pressure waterjet system (Star Burst, HJP-25005E, Sugino Machine Co., Ltd, Uozu, Japan). The pulp suspension was ejected from a 0.15 -mm diameter nozzle at $245 \mathrm{MPa}$ with 50-cycle repetitions. $\mathrm{ZnO}$ nanowires were hydrothermally synthesized based on a previously reported method, ${ }^{30}$ as follows. An aqueous solution $(100 \mathrm{~mL})$ of precursor was prepared at room temperatures from zinc nitrate hexahydrate $(25 \mathrm{mM})$, hexamethylenetetramine $(25 \mathrm{mM})$, polyethylenimine $(2.5 \mathrm{mM})$, and ammonia $(500 \mathrm{mM})$. Then, $\mathrm{ZnO}$ (thickness: ca. $75 \mathrm{~nm}$ )/Cr (thickness: ca. $7 \mathrm{~nm}$ )/Si wafer substrate (size: $2.25 \mathrm{~cm} \times 2.25 \mathrm{~cm}$ ), which was prepared by successive sputtering on the Si wafer, was immersed upside down into the precursor solution in a sealed beaker and maintained at $95{ }^{\circ} \mathrm{C}$ for $12 \mathrm{~h}$, followed by washing with distilled water and drying. The $\mathrm{ZnO}$ nanowires obtained were peeled from the substrate by ultrasonication in an aqueous dispersion of cellulose nanofibers for 3 min. Zinc nitrate hexahydrate $(>99.0 \%$ purity), hexamethylenetetramine $(>99.0 \%$ purity), and ammonia solution (28 wt\%) were purchased from Wako Pure Chemical Industries, Ltd., Osaka, Japan. Polyethylenimine solution (50 wt\%, average molecular weight: 2000) was obtained from Aldrich, Ltd., Tokyo, Japan. Si wafer (4" P(100) 1-10) and a pencil (9800, Hardness: 2B) were purchased from SUMCO corp., Tokyo, Japan, and Mitsubishi Pencil Co., Ltd, Ohi, Japan, respectively. The polyethylene terephthalate (PET) films (G2, thickness: $50 \mu \mathrm{m}$, Teijin DuPont Films Japan, Ltd., Tokyo, Japan) were treated at $150 \mathrm{~V}$ and $10 \mathrm{~mA}$ for $30 \mathrm{~s}$ with a plasma etching 
device (AP-T02-L, Sekisui Chemical Co., Ltd., Osaka, Japan) to improve their wettability before use.

Preparation of the $\mathrm{ZnO}$ nanowire/cellulose nanofiber composite networks on cellulose nanofiber paper. To prepare the $\mathrm{ZnO}$ nanowire/cellulose nanofiber composite networks on cellulose nanofiber paper, i.e., the $\mathrm{ZnO}$ nanowire@cellulose nanofiber paper, with a diameter of $35 \mathrm{~mm}$, an aqueous dispersion of cellulose nanofibers $(0.3 \mathrm{wt} \%, 20 \mathrm{~mL})$ was first dewatered on a membrane filter (H020A090C, hydrophilic polytetrafluoroethylene (PTFE) membrane, $0.1 \mu \mathrm{m}$ pore diameter, Advantec Toyo Kaisha, Ltd., Tokyo, Japan) under pressure filtration (KST-47, Advantec Toyo Kaisha, Ltd., Tokyo, Japan). Then, the aqueous mixture of cellulose nanofibers and $\mathrm{ZnO}$ nanowires at a specific concentration $(30 \mathrm{~mL})$ was added and filtered in the same manner. The obtained wet sheet was covered with a hydrophobic glass plate, treated by hot pressing at $110{ }^{\circ} \mathrm{C}$ for $1 \mathrm{~h}(8.5 \mathrm{MPa})$ and then peeled from the membrane. As a control, the $\mathrm{ZnO}$ nanowire networks on PET film were also prepared by drop coating, as follows. An aqueous dispersion of $\mathrm{ZnO}$ nanowires $(2 \mathrm{~mL})$ at a specific concentration was cast onto a PET film (diameter: $35 \mathrm{~mm}$ ), followed by drying at $50{ }^{\circ} \mathrm{C}$ for $2 \mathrm{~h}$ and then hot pressing at $110{ }^{\circ} \mathrm{C}$ for $1 \mathrm{~h}$ $(8.5 \mathrm{MPa})$.

Preparation and evaluation of the paper sensor. The paper sensor was constructed by depositing the electrode materials on the $\mathrm{ZnO}$ nanowire@cellulose nanofiber paper. A Pt electrode with a thickness of ca. $200 \mathrm{~nm}$ was deposited by a metal mask-assisted sputtering technique with sputtering power of $50 \mathrm{~W}$ in $\mathrm{Ar} 0.3 \mathrm{~Pa}$ atmosphere at room temperatures. The graphite electrode was deposited by line-drawing with a commercial pencil. The amount of deposited graphite was controlled by the number of pencil strokes. Typically, we drew the 
graphite electrode at least 30 times to ensure electrical conduction of electrode. The gap size of the electrodes was carefully controlled to be ca. $200 \mu \mathrm{m}$. The electrical conduction measurements and $\mathrm{NO}_{2}$ sensing measurements of the paper sensor and the graphite electrode were conducted on a temperature programmable probe station. All measurements were performed by a two-probe method. For the measurements, the temperature was modulated in the range of $25-200{ }^{\circ} \mathrm{C}$ by a state heater and the $\mathrm{NO}_{2}$ concentration varied in the range of 3.9-98 ppm with a mass-flow control system using dry air as a carrier gas. For $\mathrm{NO}_{2}$ sensing, the dry air $\left(\mathrm{N}_{2} 80 \%, \mathrm{O}_{2} 20 \%\right)$ was first flown for $100 \mathrm{~s}$ and then $\mathrm{NO}_{2}$ mixed with Ar was flown for $100 \mathrm{~s}$. This process was cycled 5 times and one another cycle with varying the flow time to be $300 \mathrm{~s}$ was tested for a reliability of sensing characteristics. During the gas flow, the flow rate was controlled to be $250 \mathrm{~mL} \mathrm{~min}{ }^{-1}$. The resistance values during the $\mathrm{NO}_{2}$ sensing were readout by applying $1 \mathrm{~V}$ between the contact electrodes. The $\mathrm{NO}_{2}$ sensing characteristics at different relative humidity (dry, $10 \%, 30 \%, 50 \%$, $70 \%)$ were measured at the flow rate of $1.4 \mathrm{~L} \mathrm{~min}^{-1}\left(0.4 \mathrm{~L} \mathrm{~min}^{-1}\right.$ for $\mathrm{NO}_{2}$ and $1.0 \mathrm{~L} \mathrm{~min}^{-1}$ for humidity control).

Analyses. Surface and cross-section observations were performed using a field-emission scanning electron microscope (FE-SEM, JEOL JSM-7610F) and an optical microscope (Olympus, BXFM-N22MBS-D). Compositional image analyses were conducted by energy dispersive X-ray spectrometry (EDX) fitted to the FE-SEM. To avoid charging issues that disturb the FE-SEM and EDX analysis, Pt thin films with a thickness of $10 \mathrm{~nm}$ were deposited onto the paper sensor prior to these measurements. The $\mathrm{ZnO}$ nanowire content was determined by atomic absorption spectrophotometry using a ZA3300 instrument (Hitachi High-Tech Science Corp., Tokyo, Japan). Sheet resistance values were measured using a resistivity meter with a ring-type probe (HirestaUX, MCP-HT800, Mitsubishi Chemical Analytech Co., Ltd., Chigasaki, Japan). 


\section{Associated content}

\section{Supporting Information}

An FE-SEM image of the $\mathrm{ZnO}$ nanowires hydrothermally synthesized on the $\mathrm{ZnO} / \mathrm{Cr} / \mathrm{Si}$ wafer substrate; Schematic of the preparation of the ZnO nanowire@cellulose nanofiber paper by a two-step papermaking process; Top-view FE-SEM and EDX elemental mapping images of the ZnO nanowire@cellulose nanofiber paper; Cross-section-view FE-SEM and EDX elemental mapping images of the ZnO nanowire@cellulose nanofiber paper; Optical and top-view FE-SEM images of the paper composite prepared from an aqueous mixture of $\mathrm{ZnO}$ nanowires and cellulose nanofibers by a one-step papermaking process; Temperature dependent current versus voltage characteristics of the $\mathrm{ZnO}$ nanowire@cellulose nanofiber paper with Pt electrodes; Current versus voltage characteristics of the $\mathrm{ZnO}$ nanowire@cellulose nanofiber paper with pencil-drawn graphite; Change in the resistance of the $\mathrm{ZnO}$ nanowire@cellulose nanofiber paper and the graphite electrode upon exposure to $98 \mathrm{ppm} \mathrm{NO}_{2}$ gas at $150{ }^{\circ} \mathrm{C}$.

\section{Author Information}

\section{Corresponding Authors}

*E-mail: hkoga@eco.sanken.osaka-u.ac.jp (H. K.); kazu-n@cm.kyushu-u.ac.jp (K. N.)

\section{ORCID}

Hirotaka Koga: 0000-0001-6295-1731

Kazuki Nagashima: 0000-0003-0180-816X

Tsunaki Takahashi: 0000-0002-2840-8038

Kojiro Uetani: 0000-0003-3245-6929 
Takeshi Yanagida: 0000-0003-4837-5701

\section{Author contributions}

H. K., K. N., M. N., and T. Y. designed this work. H. K. and K. N. prepared the manuscript. H. K., K. N., H. Y., G. Z., C. W., A. I., H. Y., Y. H. carried out the experiments. H. K., K. N., T. T., K. U., M. K., Y. H., M. N. and T. Y. analyzed the results and discussed the manuscript during the preparation. All authors discussed the results and implications and commented on the manuscript at all stages.

\section{Note}

The authors declare no competing financial interests.

\section{Acknowledgments}

This work was partially supported by Grants-in-Aid for Scientific Research (Grant No. 26220908 to M. N., No. 18 H02256 to H. K., No.18H01831 to K. N., No.18H05243 to Y. T., No.17H04927 to T.T.) from the Japan Society for the Promotion of Science, by the JST-Mirai R\&D Program (Grant No. JPMJMI17ED to M.N.) of the Japan Science and Technology Agency, and by the Cooperative Research Program "CORE Lab" of Network Joint Research Center for Materials and Devices: Dynamic Alliance for Open Innovation Bridging Human, Environment and Materials (H. K.). K.N. was supported by the MEXT Project of Integrated Research Consortium on Chemical Sciences. K.N. acknowledges IMRA Japan Co. Ltd. for financial support. We thank Andrew Jackson, PhD, from Edanz Group (www.edanzediting.com/ac) for editing a draft of this manuscript. 


\section{References}

1. Swan, M. Sensor Mania! The Internet of Things, Wearable Computing, Objective Metrics, and the Quantified Self 2.0. J. Sens. Actuator Netw. 2012, 1, 217-253.

2. Potyrailo, R. A. Multivariable Sensors for Ubiquitous Monitoring of Gases in the Era of Internet of Things and Industrial Internet. Chem. Rev. 2016, 116, 11877-11923.

3. Bogue, R. Towards the Trillion Sensors Market. Sens. Rev. 2014, 34, 137-142.

4. Zhang, J. X. J.; Hoshino, K. Molecular Sensors and Nanodevices: Principles, Designs and Applications in Biomedical Engineering: 2nd Edition; Academic Press: Cambridge, 2018.

5. Wyszynski, B.; Yatabe, R.; Nakao, A.; Nakatani, M.; Oki, A.; Oka, H.; Toko, K. Array of Chemosensitive Resistors with Composites of Gas Chromatography (GC) Materials and Carbon Black for Detection and Recognition of VOCs: A Basic Study. Sensors 2017, 17, 1606.

6. Ping, J.; Fan, Z.; Sindoro, M.; Ying, Y.; Zhang, H. Recent Advances in Sensing Applications of Two-Dimensional Transition Metal Dichalcogenide Nanosheets and Their Composites. Adv. Funct. Mater. 2017, 27, 1605817.

7. Broza, Y. Y.; Haick, H. Nanomaterial-Based Sensors for Detection of Disease by Volatile Organic Compounds. Nanomedicine 2013, 8, 785-806.

8. Korotcenkov, G. Metal Oxides for Solid-State Gas Sensors: What Determines Our Choice? Mater. Sci. Eng. B 2007, 139, 1-23.

9. Rüffer, D.; Hoehne, F.; Bühler, J. New Digital Metal-Oxide $\left(\mathrm{MO}_{\mathrm{x}}\right)$ Sensor Platform. Sensors 2018, 18, 1052.

10. Umar, A.; Hahn, Y. -B. Metal Oxide Nanostructures and Their Applications; American Scientific Publishers: Valencia, 2010.

11. Lee, S.P. Electrodes for Semiconductor Gas Sensors. Sensors 2017, 17, 683. 
12. Nogi, M.; Iwamoto, S.; Nakagaito, A. N.; Yano, H. Optically Transparent Nanofiber Paper. Adv. Mater. 2009, 21, 1595-1598.

13. Nogi, M.; Kim, C.; Sugahara, T.; Inui, T.; Takahashi, T.; Suganuma, K. High Thermal Stability of Optical Transparency in Cellulose Nanofiber Paper. Appl. Phys. Lett. 2013, 102, 181911.

14. Hu, L. B.; Zheng, G. Y.; Yao, J.; Liu, N. A.; Weil, B.; Eskilsson, M.; Karabulut, E.; Ruan, Z. C.; Fan, S. H.; Bloking, J. T.; McGehee, M. D.; Wagberg, L.; Cui, Y. Transparent and Conductive Paper from Nanocellulose Fibers. Energy Environ. Sci. 2013, 6, 513-518.

15. Koga, H.; Nogi, M.; Komoda, N.; Nge, T. T.; Sugahara, T.; Suganuma, K. Uniformly Connected Conductive Networks on Cellulose Nanofiber Paper for Transparent Paper Electronics. NPG. Asia Mater. 2014, 6, e93.

16. Huang, J.; Zhu, H.; Chen, Y.; Preston, C.; Rohrbach, K.; Cumings, J.; Hu, L. Highly Transparent and Flexible Nanopaper Transistors. ACS Nano 2013, 7, 2106-2113.

17. Fujisaki, Y.; Koga, H.; Nakajima, Y.; Nakata, M.; Tsuji, H.; Yamamoto, T.; Kurita, T.; Nogi, M.; Shimidzu, N. Transparent Nanopaper-Based Flexible Organic Thin-Film Transistor Array. Adv. Funct. Mater. 2014, 24, 1657-1663.

18. Zhu, H.; Narakathu, B. B.; Fang, Z.; Aijazi, A. T.; Joyce, M.; Atashbar, M.; Hu, L. A Gravure Printed Antenna on Shape-Stable Transparent Nanopaper. Nanoscale 2014, 6, $9110-9115$.

19. Inui, T.; Koga, H.; Nogi, M.; Komoda, N.; Suganuma, K. A Miniaturized Flexible Antenna Printed on a High Dielectric Constant Nanopaper Composite. Adv. Mater. 2015, 27, 11121116. 
20. Nagashima, K.; Koga, H.; Celano, U.; Zhuge, F.; Kanai, M.; Rahong, S.; Meng, G.; He, Y.; Boeck, J. D.; Jurczak, M.; Vandervorst, W.; Kitaoka, T.; Nogi, M.; Yanagida, T. Cellulose Nanofiber Paper as an Ultra Flexible Nonvolatile Memory. Sci. Rep. 2014, 4, 5532.

21. Lee, B. -H.; Lee, D. -I.; Bae, H.; Seong, H.; Jeon, S. -B.; Seol, M. -L.; Han, J. -W., Meyyappan, M.; Im, S. -G.; Choi, Y. -K. Foldable and Disposable Memory on Paper. Sci. Rep. 2016, 6, 38389.

22. Zhong, J.; Zhu, H.; Zhong, Q.; Dai, J.; Li, W.; Jiang, S.-H.; Yao, Y.; Henderson, D.; Hu, Q.; Hu, L. Self-Powered Human Interactive Transparent Nanopaper Systems. ACS Nano 2015, 9, $7399-7406$.

23. Koga, H.; Nogi, M.; Isogai, A. Ionic Liquid Mediated Dispersion and Support of Functional Molecules on Cellulose Fibers for Stimuli-Responsive Chromic Paper Devices. ACS Appl. Mater. Interfaces 2017, 9, 40914-40920.

24. Jung, Y. H.; Chang, T.-H.; Zhang, H.; Yao, C.; Zheng, Q.; Yang, V. W.; Mi, H.; Kim, M.; Cho, S. J.; Park, D.-W. High-Performance Green Flexible Electronics Based on Biodegradable Cellulose Nanofibril Paper. Nat. Commun. 2015, 6, 7170.

25. Celano, U.; Nagashima, K.; Koga, H.; Nogi, M.; Zhuge, F.; Meng, G.; He, Y.; De Boeck, J.; Jurczak, M.; Vandervorst, W.; Yanagida, T. All-Nanocellulose Nonvolatile Resistive Memory. NPG Asia Mater. 2016, 8, e310.

26. Kim, K.; Song, Y.W.; Chang, S.; Kim, I.H.; Kim, S.; Lee, S.Y. Fabrication and Characterization of Ga-Doped ZnO Nanowire Gas Sensor for the Detection of CO. Thin Solid Films 2009, 518, 1190-1193.

27. Woo, H. S.; Kwak, C. H.; Kim, I. D.; Lee, J. H. Selective, Sensitive, and Reversible $\mathrm{H}_{2} \mathrm{~S}$ Sensors Using Mo-Doped ZnO Nanowire Network Sensors J. Mater. Chem. A 2014, 2, 6412-6418. 
28. Woo, H. -S.; Kwak, C. -H.; Chung, J. -H.; Lee, J. -H. Highly Selective and Sensitive Xylene Sensors Using Ni-Doped Branched ZnO Nanowire Networks. Sens. Actuators, B 2015, 216, $358-366$.

29. Chen, C. Q.; Shi, Y.; Zhang, Y. S.; Zhu, J.; Yan, Y. J. Size Dependence of Young's Modulus in ZnO Nanowires. Phys. Rev. Lett. 2006, 96, 075505.

30. He, Y.; Yanagida, T.; Nagashima, K.; Zhuge, F.; Meng, G.; Xu, B.; Klamchuen, A.; Rahong, S.; Kanai, M.; Li, X.; Suzuki, M.; Kai, S.; Kawai, T. Crystal-Plane Dependence of Critical Concentration for Nucleation on Hydrothermal ZnO Nanowires. J. Phys. Chem. C 2013, 117, $1197-1203$.

31. Ahn, M. W.; Park, K. S.; Heo, J. H.; Kim, D.-W.; Choi, K. J.; Park, J.-G. On-Chip Fabrication of ZnO-Nanowire Gas Sensor with High Gas Sensitivity. Sens. Actuators, B 2009, 138, 168-173.

32. Kumar, R.; Al-Dossary, O.; Kumar, G.; Umar, A. Zinc Oxide Nanostructures for $\mathrm{NO}_{2}$ GasSensor Applications: A Review. Nano-Micro Lett. 2015, 7, 97-120.

33. Lin, C. -W.; Zhao, Z.; Kim, J.; Huang, J. Pencil Drawn Strain Gauges and Chemiresistors on Paper. Sci. Rep. 2014, 4, 3812. 

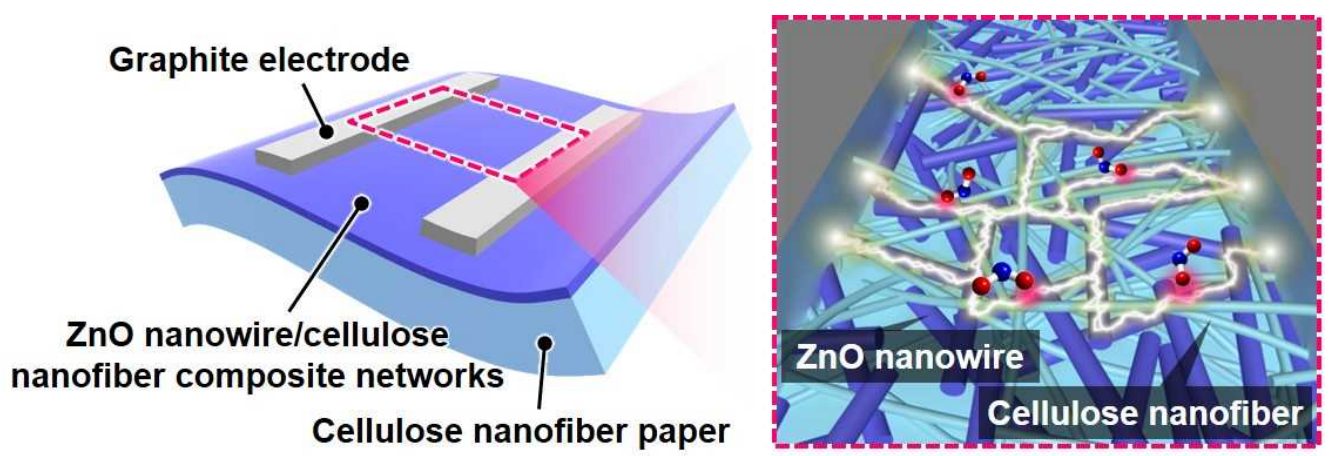

Figure 1. Schematic of the disposable molecular sensor device consisting of a cellulose nanofiber paper substrate, a $\mathrm{ZnO}$ nanowire sensor, and a graphite electrode. 


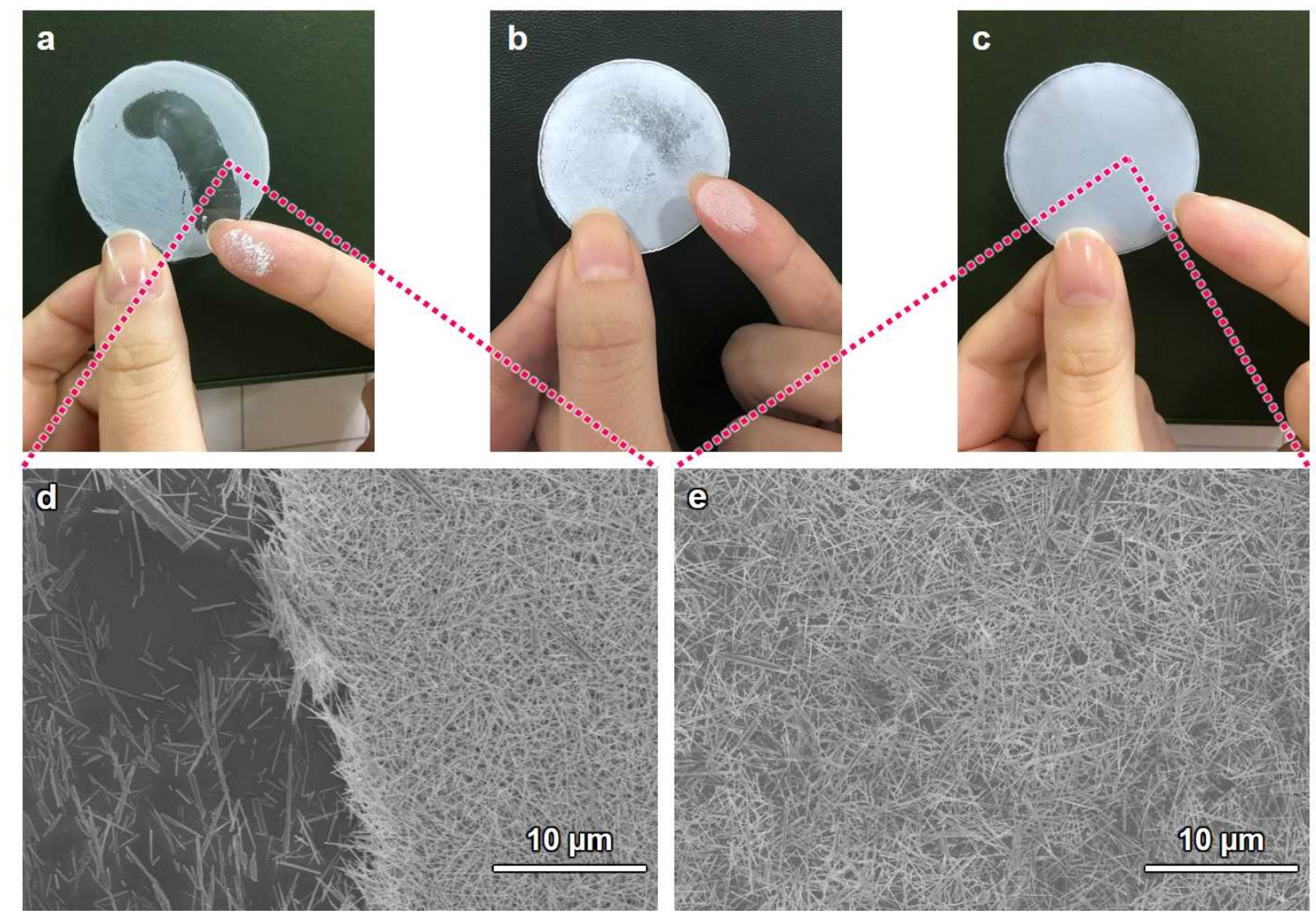

Figure 2. Adhesion performance of the $\mathrm{ZnO}$ nanowire/cellulose nanofiber composite networks on a cellulose nanofiber paper substrate. (a, b, c) Optical and (d, e) FE-SEM images of (a, d) ZnO nanowires on a PET film substrate, (b) $\mathrm{ZnO}$ nanowires on a cellulose nanofiber paper substrate, and (c, e) $\mathrm{ZnO}$ nanowire/cellulose nanofiber composite networks on a cellulose nanofiber paper substrate after running a finger over their surfaces. In each case, hot pressing was conducted at $110^{\circ} \mathrm{C}$ for $1 \mathrm{~h}(8.5 \mathrm{MPa})$ before adhesion performance testing. 
a

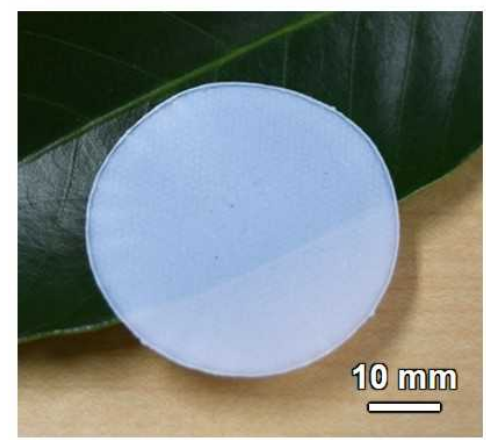

c

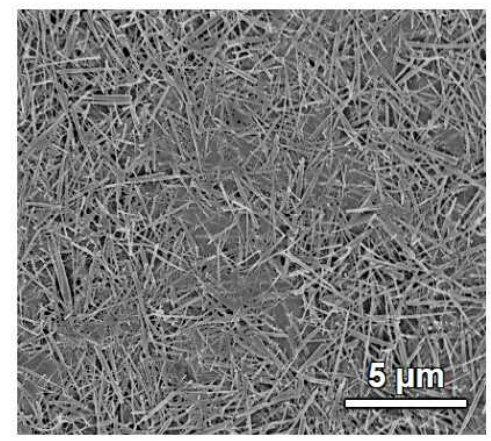

e

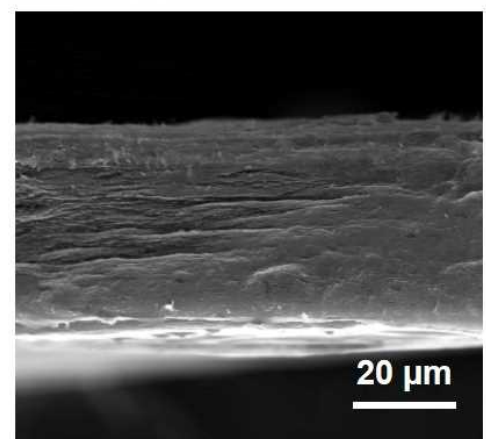

b

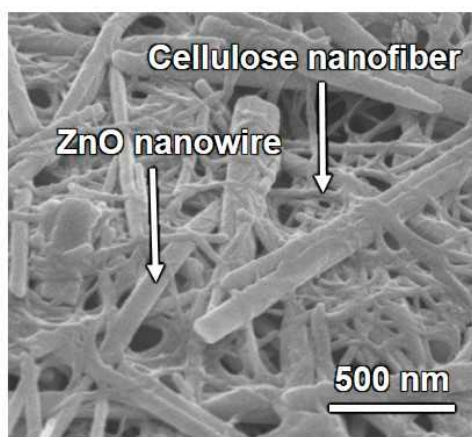

d

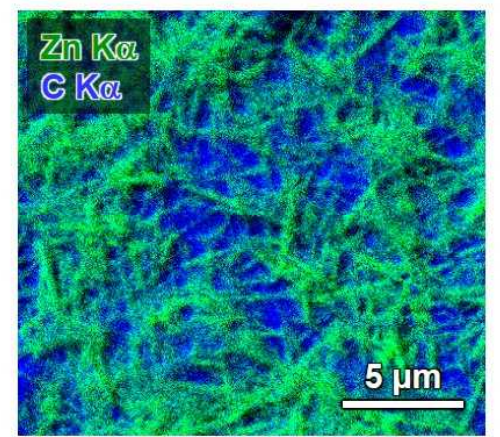

f

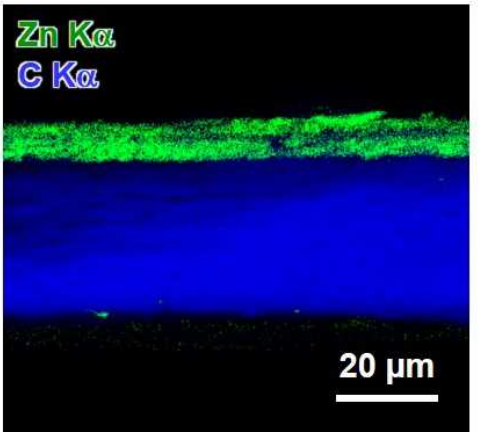

Figure 3. Characterization of the $\mathrm{ZnO}$ nanowire/cellulose nanofiber composite networks on a cellulose nanofiber paper substrate, denoted the $\mathrm{ZnO}$ nanowire@cellulose nanofiber paper. (a) optical, (b) top-view FE-SEM, (c, d) top-view, and (e, f) cross-section FE-SEM and EDX mapping images of the $\mathrm{ZnO}$ nanowire@cellulose nanofiber paper. Paper size: 35-mm diameter. 
a

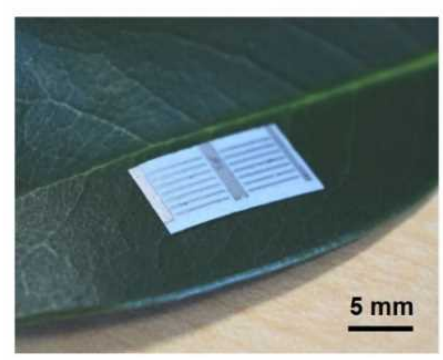

c

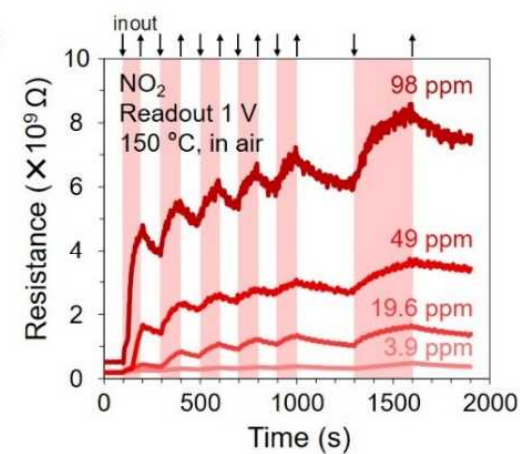

e

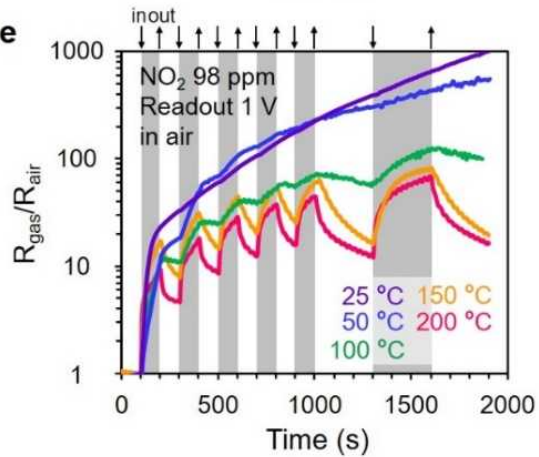

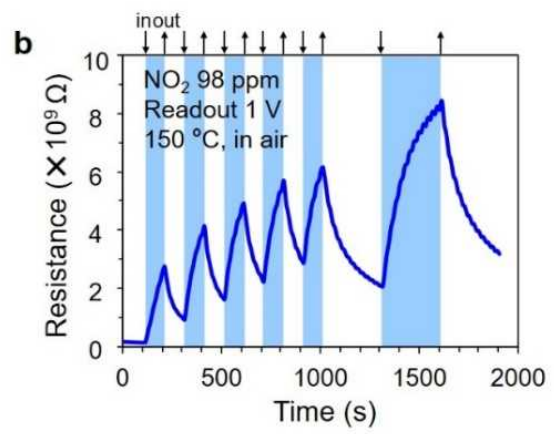

d

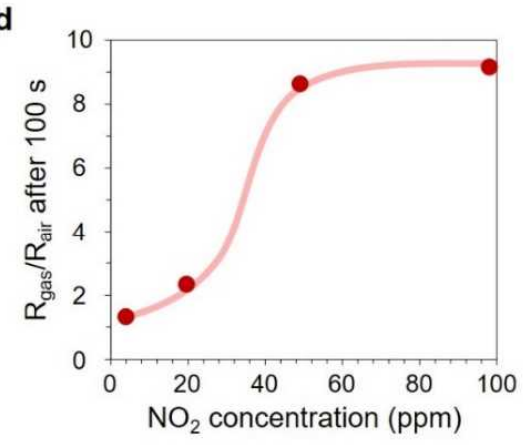

f

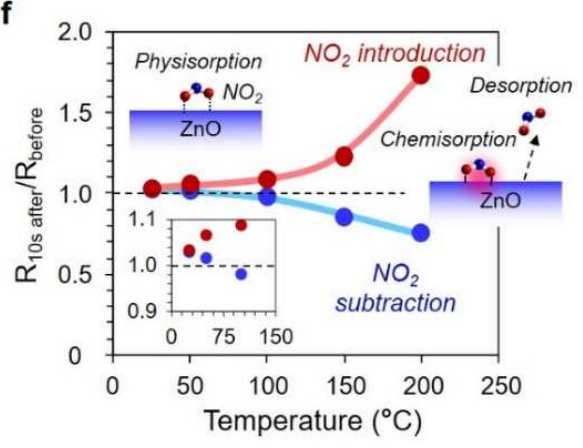

Figure 4. $\mathrm{NO}_{2}$ sensing performances of the paper sensor consisting of $\mathrm{ZnO}$ nanowire@cellulose nanofiber paper and Pt electrodes under dry condition. (a) A photograph of sensor, (b) resistance versus time on exposure to $98 \mathrm{ppm} \mathrm{NO}_{2}$ gas at $150{ }^{\circ} \mathrm{C}$, (c) resistance versus time upon exposure to $\mathrm{NO}_{2}$ gas with concentrations ranging from 3.9 to $98 \mathrm{ppm}$ at $150{ }^{\circ} \mathrm{C}$, (d) relative resistance change upon exposure to $\mathrm{NO}_{2}$ gas with concentrations ranging from 3.9 to $98 \mathrm{ppm}$ at $150{ }^{\circ} \mathrm{C}$ for $100 \mathrm{~s}$, (e) relative resistance change versus time upon exposure to $98 \mathrm{ppm} \mathrm{NO}_{2}$ gas at temperatures ranging from 25 to $200{ }^{\circ} \mathrm{C}$, (f) relative resistance change upon exposure to $98 \mathrm{ppm}$ $\mathrm{NO}_{2}$ gas for $10 \mathrm{~s}$ (red) and the following exposure to air for $10 \mathrm{~s}$ (blue) at temperatures ranging from 25 to $200{ }^{\circ} \mathrm{C}$. 

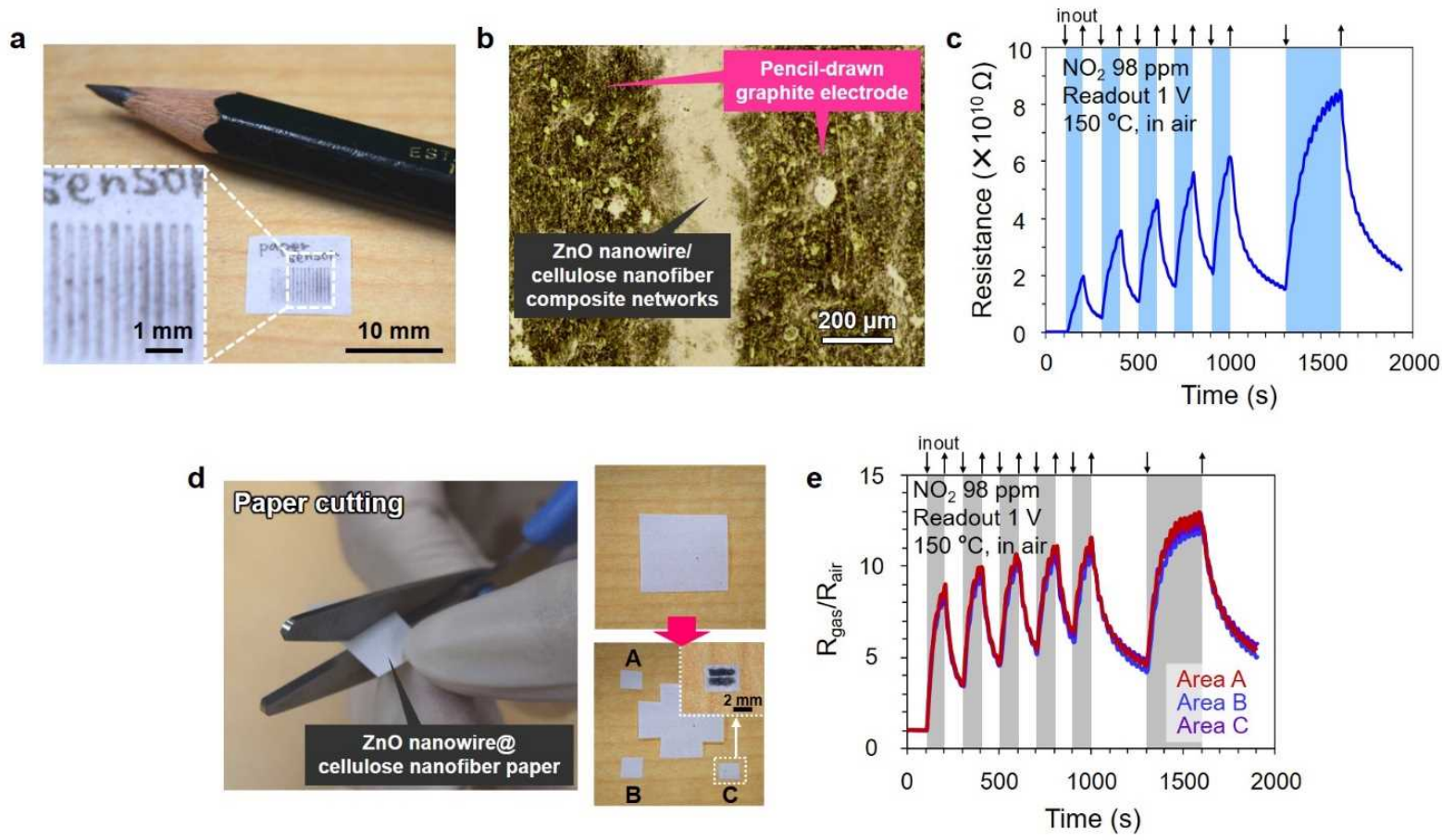

Figure 5. $\mathrm{NO}_{2}$ sensing performances under dry condition and paper-like usability of the paper sensor consisting of the $\mathrm{ZnO}$ nanowire@cellulose nanofiber paper and the pencil-drawn graphite electrodes. (a) Optical and (b) optical microscope images, (c) resistance versus time upon exposure to $98 \mathrm{ppm} \mathrm{NO}_{2}$ gas at $150{ }^{\circ} \mathrm{C}$, (d) fabrication of the paper sensor by scissor-cutting and pencil-drawing, (e) influence of cutting position of the ZnO nanowire@cellulose nanofiber paper on the $\mathrm{NO}_{2}$ sensing performance of the paper sensors. 

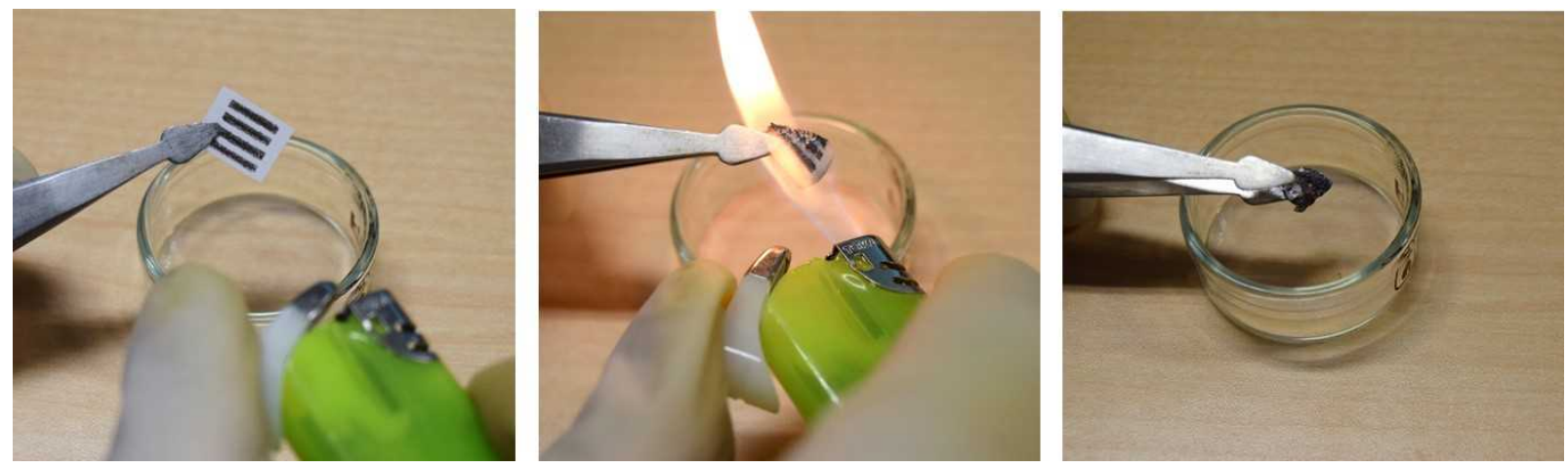

Figure 6. Disposability test by burning of the paper sensor consisting of the $\mathrm{ZnO}$ nanowire@cellulose nanofiber paper and the pencil-drawn graphite electrodes. 
Table of Contents Graphic
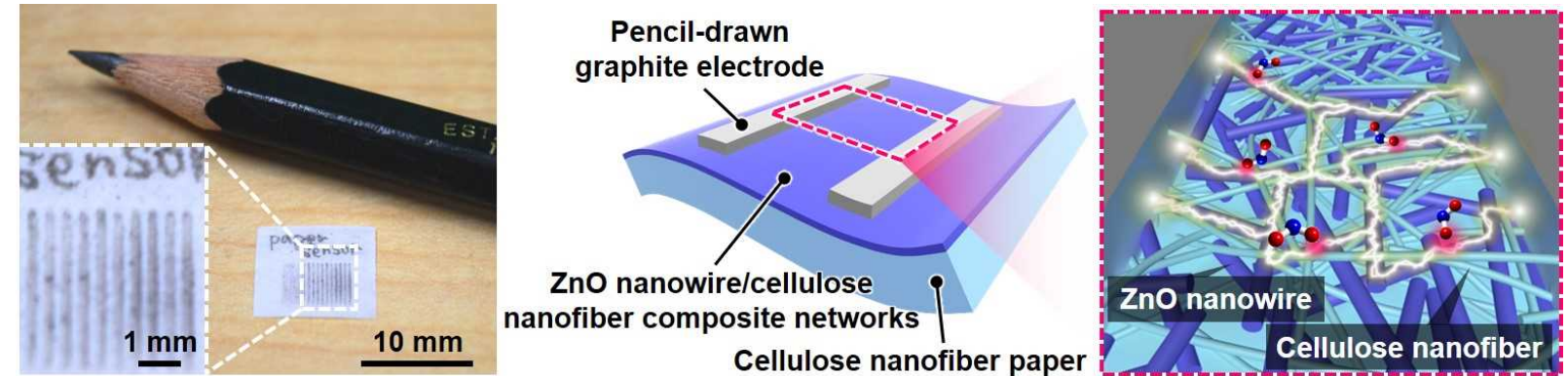


\section{Supporting Information}

\section{Paper-based disposable molecular sensor constructed from oxide nanowires, cellulose nanofibers, and pencil-drawn electrodes}

Hirotaka Koga, ${ }^{*, \dagger}$ Kazuki Nagashima, ${ }^{*}$, Yintong Huang§, Guozhu Zhang, ${ }^{\ddagger}$ Chen Wang, ${ }^{\ddagger}$ Tsunaki Takahashi, ${ }^{\ddagger}$ Akihide Inoue, ${ }^{\star}$ Hong Yang, ${ }^{\ddagger}$ Masaki Kanai, ${ }^{\star}$ Yong He,\| Kojiro Uetani, ${ }^{\dagger}$ Masaya Nogi, ${ }^{\dagger}$ and Takeshi Yanagida

†The Institute of Scientific and Industrial Research, Osaka University, 8-1 Mihogaoka, Ibaraki, Osaka 567-0047, Japan

\#nstitute for Materials Chemistry and Engineering, Kyushu University, 6-1 Kasuga-Koen, Kasuga, Fukuoka 816-8580, Japan

§Graduate School of Engineering, Osaka University, 8-1 Mihogaoka, Ibaraki, Osaka, 567-0047, Japan

$\|$ Key Laboratory of Optoelectronic Technology and Systems of the Education Ministry of China, College of Optoelectronic Engineering, Chongqing University, Chongqing, 400044, China

Corresponding Authors

*E-mail: hkoga@eco.sanken.osaka-u.ac.jp (H. K.); kazu-n@cm.kyushu-u.ac.jp (K. N.) 


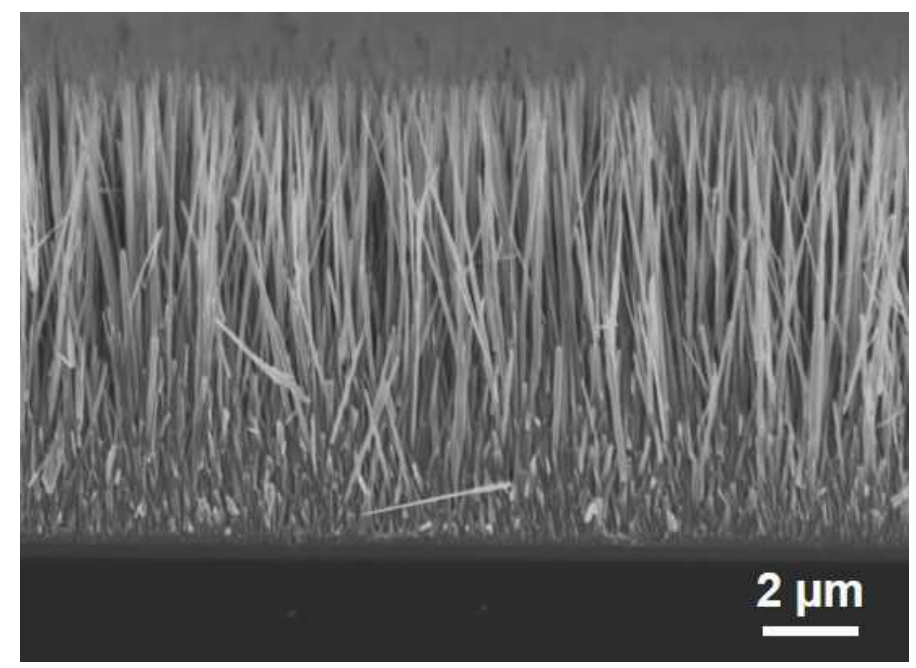

Figure S1. FE-SEM image of the $\mathrm{ZnO}$ nanowires hydrothermally synthesized on the $\mathrm{ZnO} / \mathrm{Cr} / \mathrm{Si}$ wafer substrate.

The $\mathrm{ZnO}$ nanowires were peeled from the wafer by ultrasonication in an aqueous dispersion of cellulose nanofibers for $3 \mathrm{~min}$, and then used to prepare the $\mathrm{ZnO}$ nanowire/cellulose nanofiber composite networks on a cellulose nanofiber paper substrate. After peeling from the wafer by ultrasonication, the widths and length of the $\mathrm{ZnO}$ nanowires were approximately $100 \mathrm{~nm}$ and 6 $\mu \mathrm{m}$, respectively. 


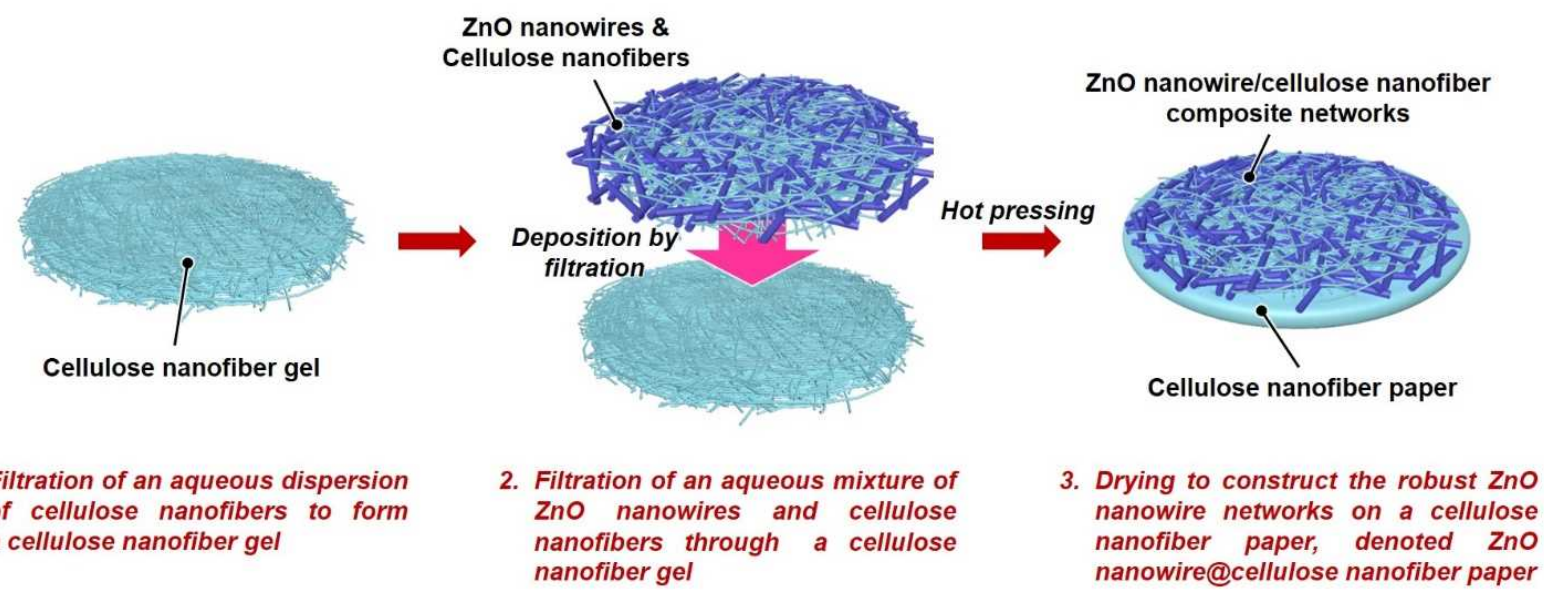

Figure S2. Schematic diagram of the preparation of the $\mathrm{ZnO}$ nanowire/cellulose nanofiber composite networks on cellulose nanofiber paper (denoted $\mathrm{ZnO}$ nanowire@cellulose nanofiber paper) by a two-step papermaking process. 

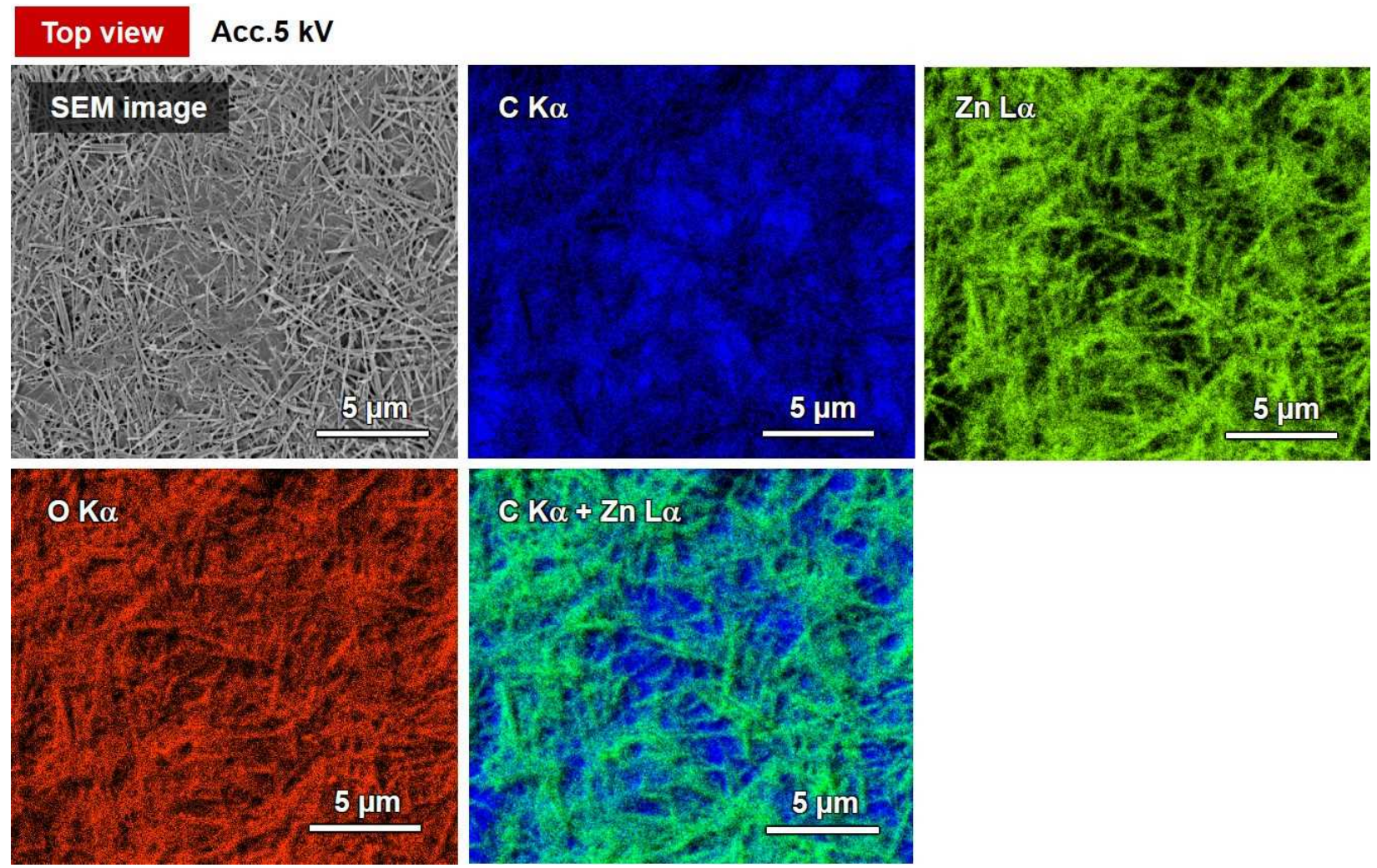

Figure S3. Top-view FE-SEM and EDX elemental mapping images of the $\mathrm{ZnO}$ nanowire@cellulose nanofiber paper. 


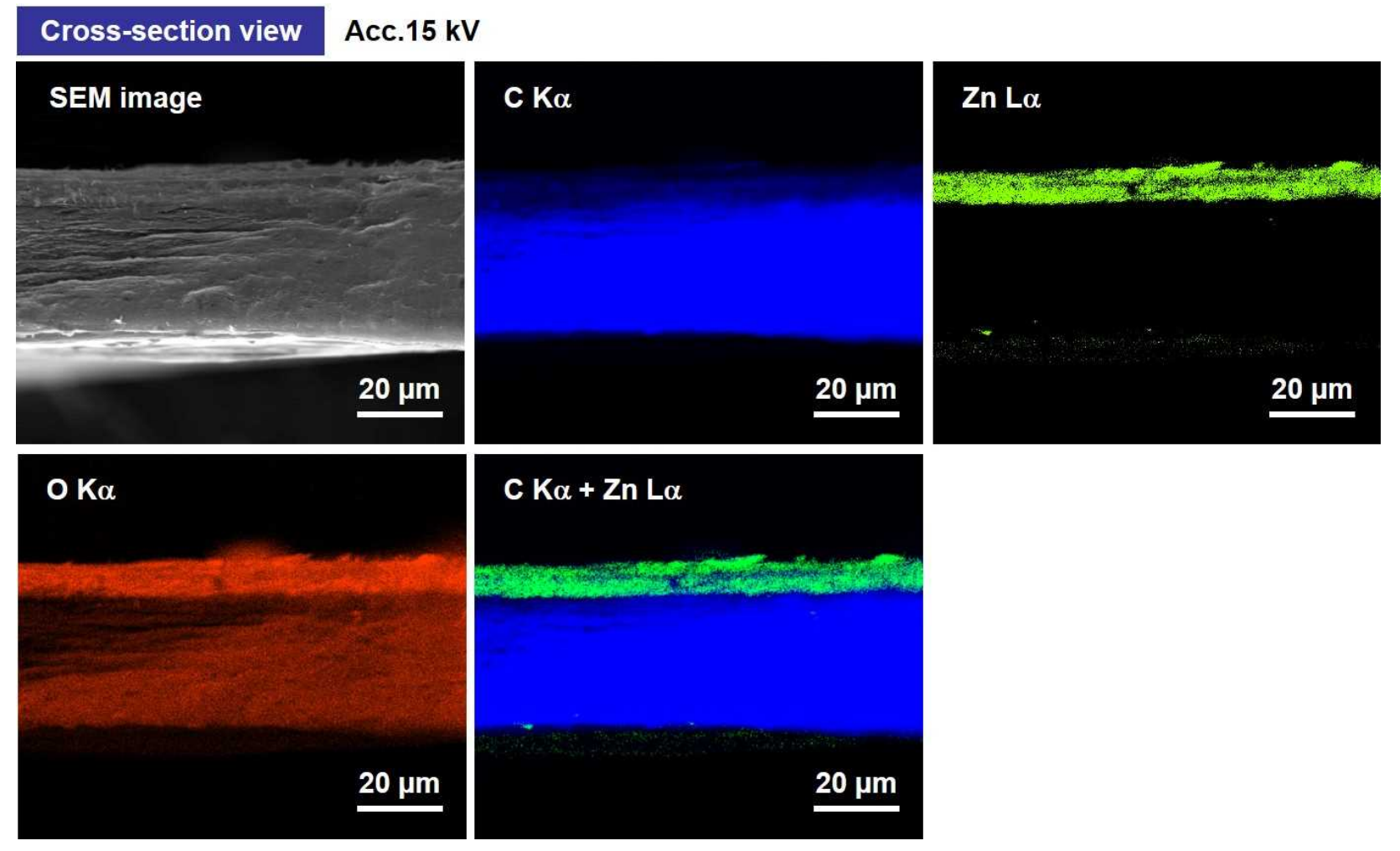

Figure S4. Cross section-view FE-SEM and EDX elemental mapping images of the $\mathrm{ZnO}$ nanowire@cellulose nanofiber paper. 

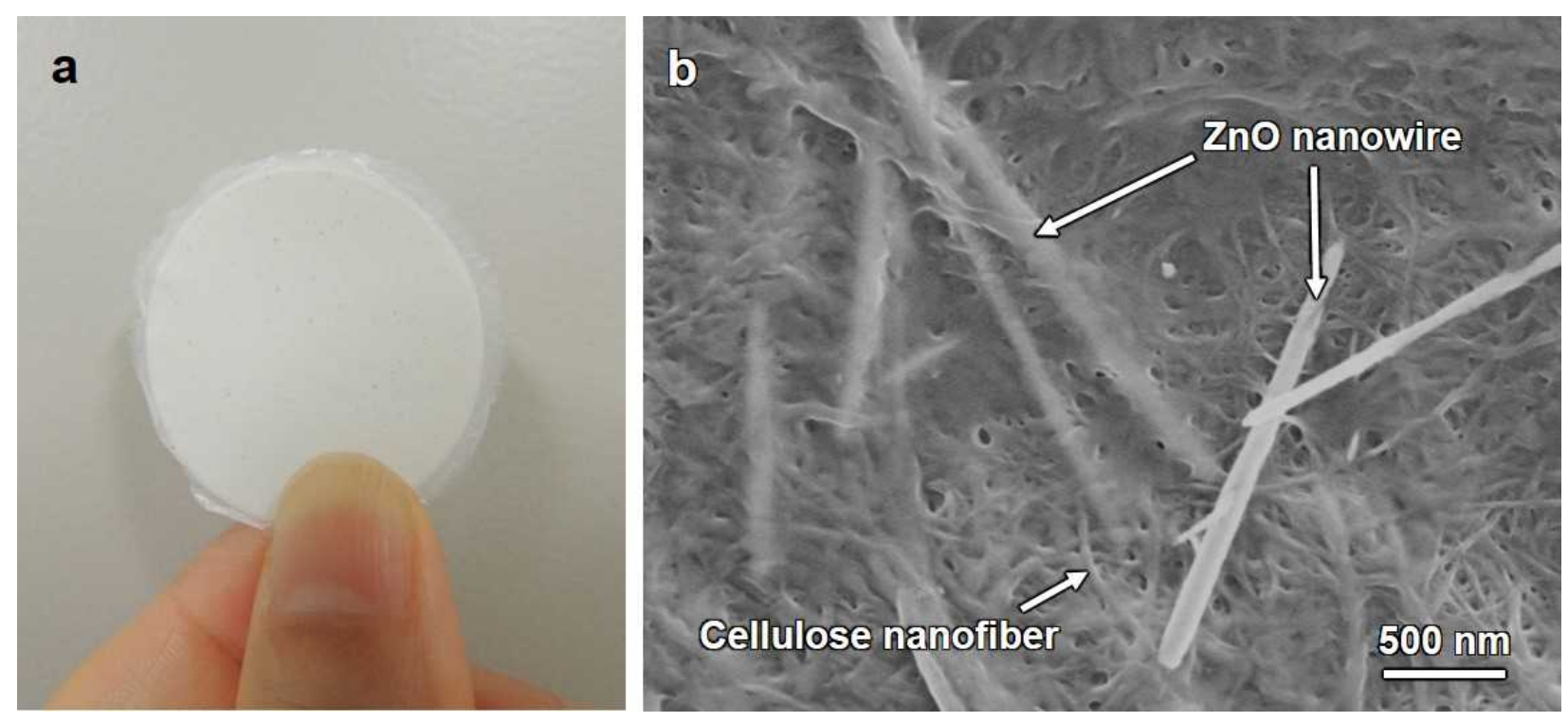

Figure S5. (a) Optical and (b) top-view FE-SEM images of the paper composite prepared from an aqueous mixture of $\mathrm{ZnO}$ nanowires and cellulose nanofibers by a one-step papermaking process. For the paper composite prepared from the simple mixture of $\mathrm{ZnO}$ nanowires and cellulose nanofibers, most of $\mathrm{ZnO}$ nanowires were buried inside the cellulose nanofiber matrix, resulting in a high surface resistance comparable to that of the cellulose nanofiber paper without $\mathrm{ZnO}$ nanowires. These results suggested that this simple mixing approach prevents the formation of the nanowire sensing networks on the surfaces of the cellulose nanofiber paper substrate. 


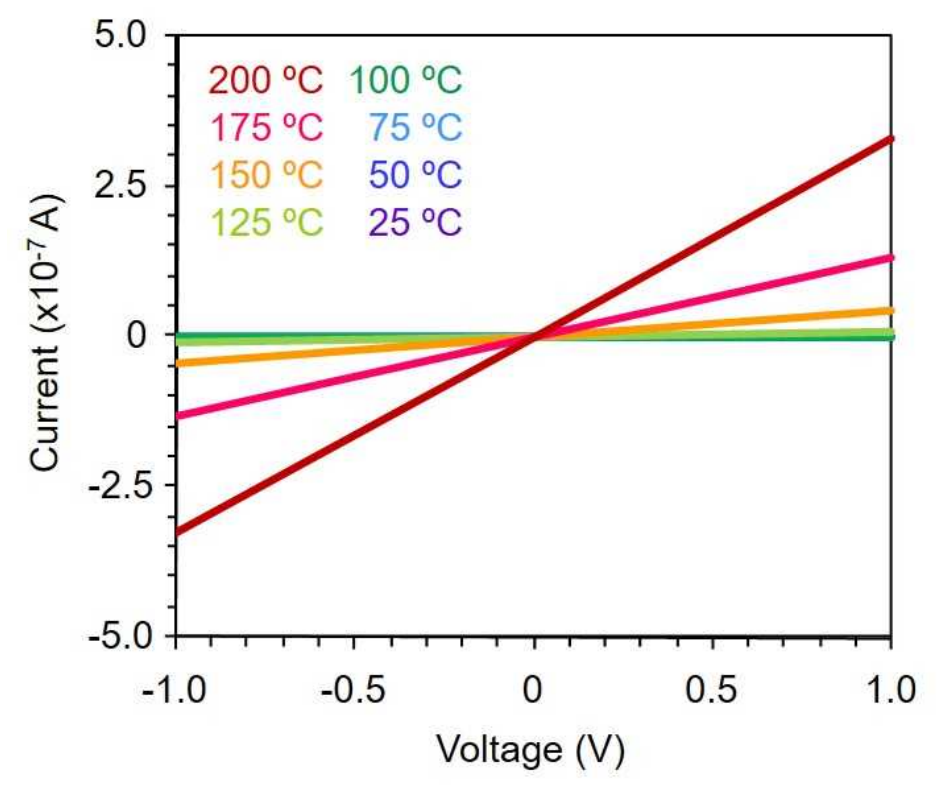

Figure S6. Temperature dependent current versus voltage characteristics of the $\mathrm{ZnO}$ nanowire@cellulose nanofiber paper. Electrode: sputtered Pt. 


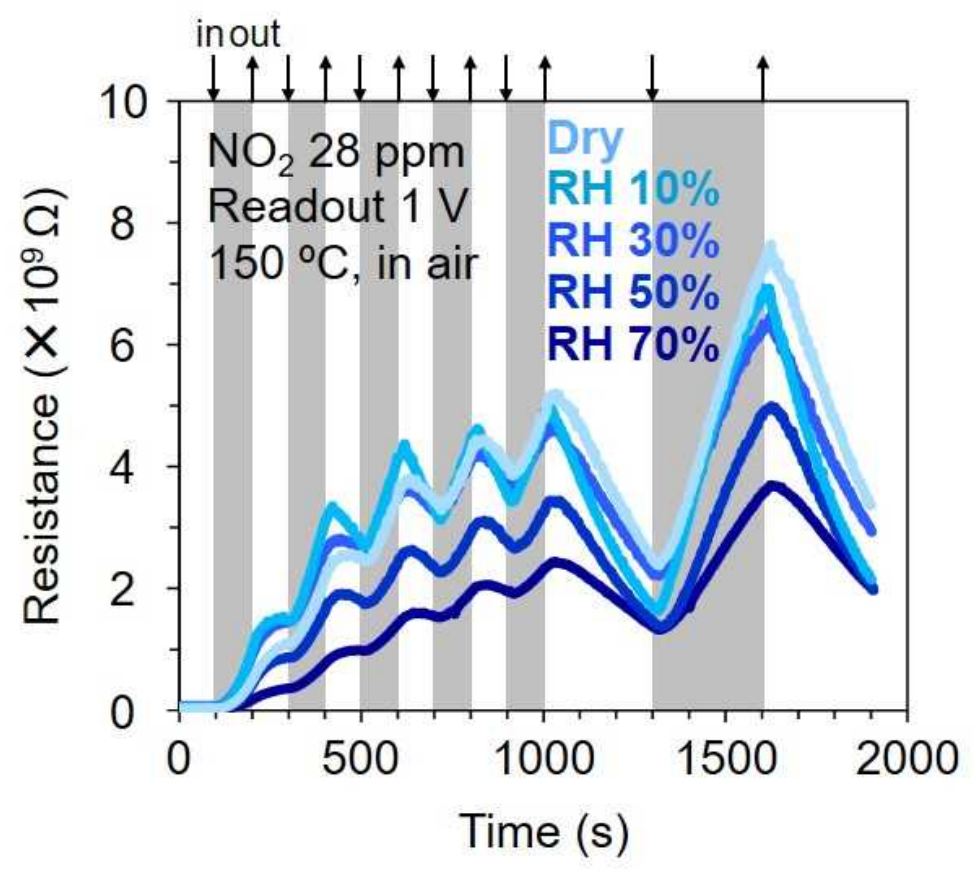

Figure S7. Effect of relative humidity $(\mathrm{RH})$ on the $\mathrm{NO}_{2}$ sensing performances of the paper sensor consisting of ZnO nanowire@cellulose nanofiber paper and Pt electrodes. 


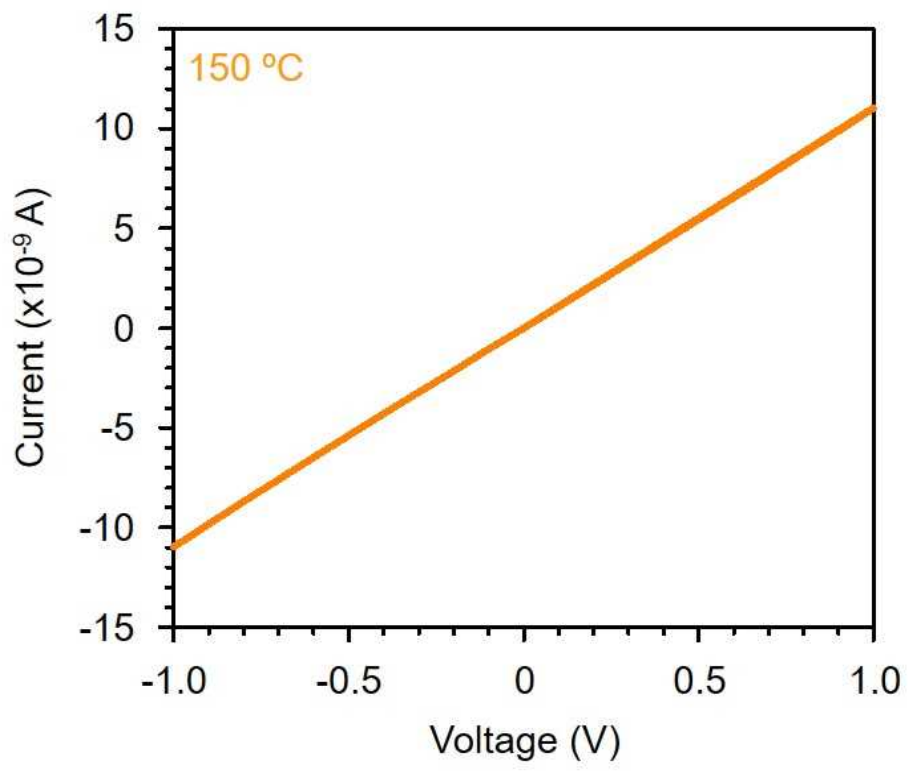

Figure S8. Current versus voltage characteristics of the $\mathrm{ZnO}$ nanowire@cellulose nanofiber paper. Electrode: pencil-drawn graphite. 

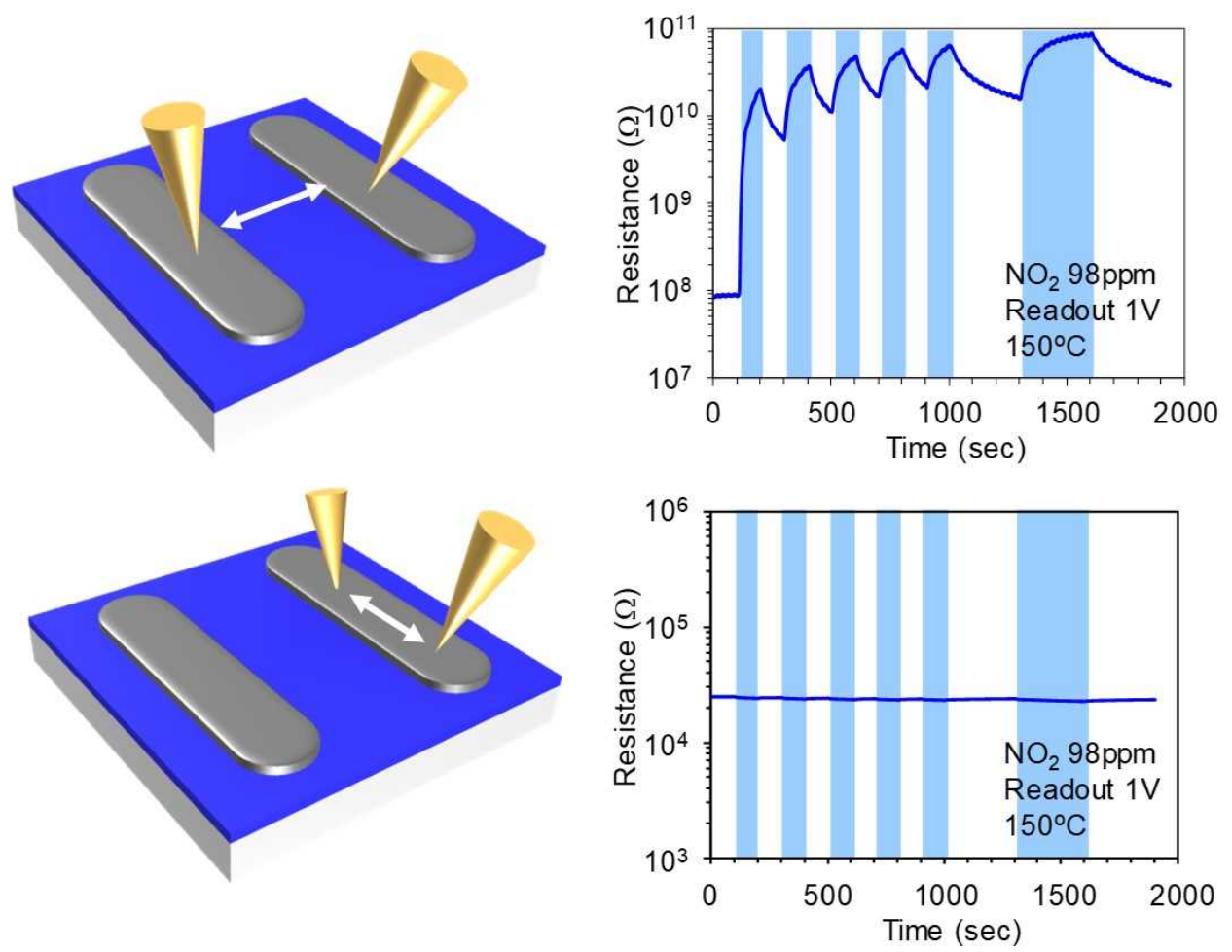

Figure S9. $\mathrm{NO}_{2}$ sensing performance of the paper sensor consisting of the $\mathrm{ZnO}$ nanowire@cellulose nanofiber paper and the pencil-drawn graphite electrodes. Change in the resistance of the $\mathrm{ZnO}$ nanowire@cellulose nanofiber paper (top) and the graphite electrode (bottom) upon exposure to $98 \mathrm{ppm} \mathrm{NO}_{2}$ gas at $150{ }^{\circ} \mathrm{C}$. 